\title{
Cross-section of subsea umbilical and stress prediction of its structural components
}

\author{
$V$. V. Solovev ${ }^{1, *}, P$. N. Zyatikov ${ }^{1}$, and $I$. N. Kozyrev ${ }^{1}$ \\ ${ }^{1}$ National Research Tomsk Polytechnic University, 634050 Tomsk, Russia
}

\begin{abstract}
It is presented in this article analysis of two models of subsea umbilicals under axial stress. Subsea umbilicals play a crucial role in offshore petroleum production and are designed to withstand all the environmental dynamic loads during the production period as long as 25 years. Apart from dynamic loads subsea umbilicals are under thermal loads as well having impact on the structural components and changing the material properties in some cases. The cross-section arrangement is a major part of the entire process of subsea umbilicals design. That is why this research is focused on the design of cross-section and has an aim to calculate main impacts subsea umbilicals facing during exploitation.
\end{abstract}

\section{Introduction}

Global energy market has been significantly grown for the last 30 years which means ordinary onshore methods of production, exploration and development will face with a challenge to meet the demand. One of the potential ways to meet this constantly growing demand is to develop offshore oil and gas fields, where it requires to use reliable equipment being able to withstand all the loads for as long as 20 or 25 years. One of the most important components in offshore production system is a subsea umbilical, that is why it is necessary to perform a quality structural analysis before manufacturing to insure it suits the project conditions.

This research is focused on two different configurations of subsea umbilical with five bounded hoses same diameter made of stainless steel. These hoses are used to transport hydraulic liquids, inhibitors and some other chemicals from offshore platform towards subsea production facilities to provide the continuity of the production process and improve its integrity.

\section{Cross section design}

The inner diameter was chosen based on the ones provided by one of the manufactures presented on the market (see Table 1).

${ }^{*}$ Corresponding author: solowyev@gmail.com 
Table 1. Stainless steel hoses sizes range.

\begin{tabular}{|c|c|c|c|}
\hline \multicolumn{2}{|c|}{ Inner Diameter } & \multicolumn{2}{c|}{ Wall thickness (mm) } \\
\hline Inches & $\mathrm{mm}$ & minimum & maximum \\
\hline $3 / 4$ & 19.05 & 1.1 & 4 \\
\hline
\end{tabular}

Designed and researched cross section designs are shown in Figure 1. The analysis was made to find the behavior of subsea umbilical under two main loads: axial and bending. The results for bending stress is not represented in this article, but will be discussed later.

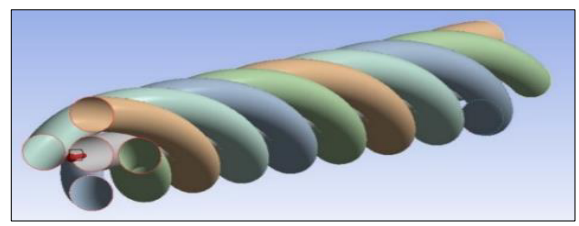

a)

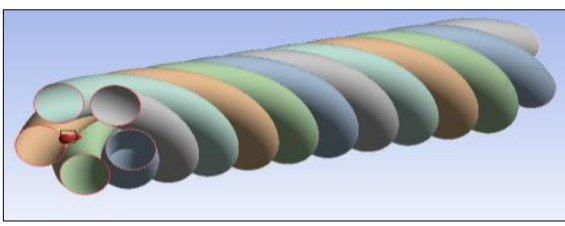

b)

Fig. 1. Two models in axial loads simulation, where red arrows show the active axial force applied to one of the end of each umbilical: a) First Model; b) Second Model.

\section{Simulation results discussion}

As it is shown in the Figure 2, the second model experienced smaller both the minimum and maximum loads under all five stages of stresses. However, under axial force of $15 \mathrm{kN}$ both model show almost equal results of maximum stress (221 MPa and 209.77MPa, for the first and second models, respectively). The most obvious reason for this might be the yield stress of stain steel, which is $210 \mathrm{MPa}$ according to the ANSYS materials database. When the applied force was between $10 \mathrm{kN}$ and $15 \mathrm{kN}$ the first model started to experience plastic deformation. However, the second model started to deform plastically under a much higher force of about $20 \mathrm{kN}$. Considering that both models consist of the same size hoses made of the same material, the only reason for such results can be the difference in structure of cross section. The second model structure can withstand a higher axial stress. The difference between starts of the plastic deformation of two models is around $5 \mathrm{kN}$. Graphically the results are presented in Figure 3 below.

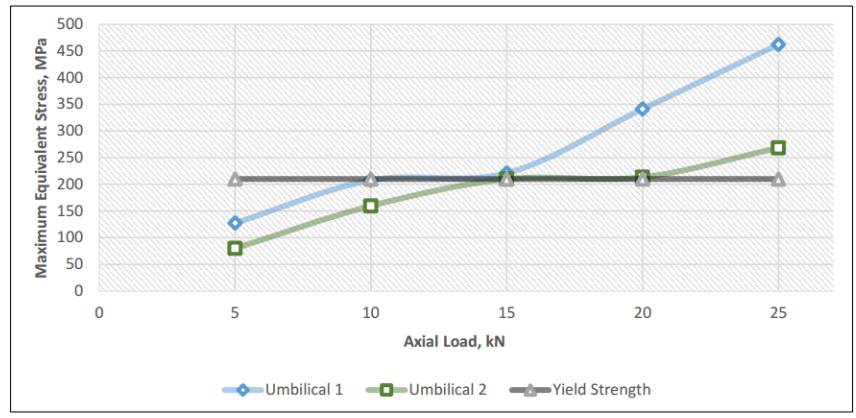

Fig. 2. Maximum Equivalent Stress (MPa) to Axial Load (kN). 


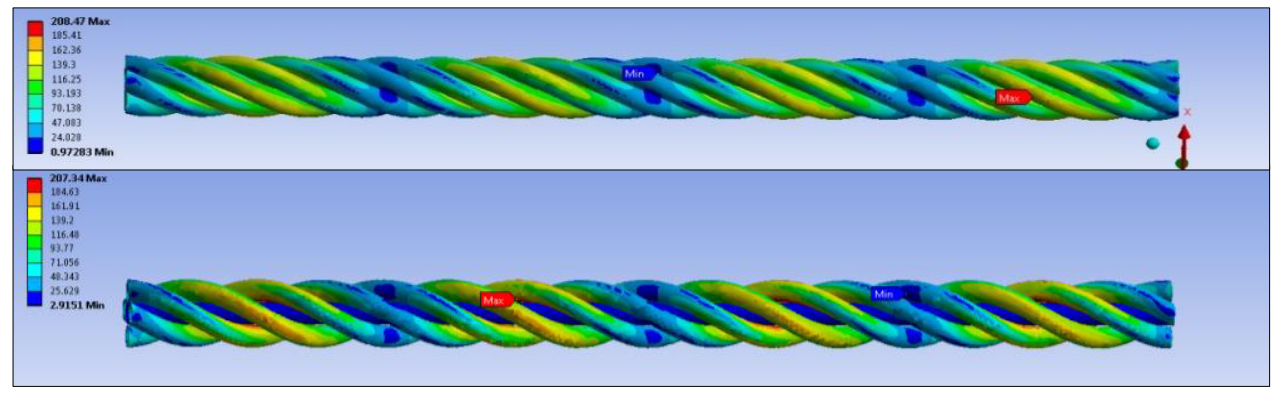

Fig. 3. Two Umbilicals Axial Stress (MPa) Pattern.

\section{Analytical calculation}

The next step of this research is the verification of the results obtained from computer simulation which can be done by analytical calculations or by experiments. It is not possible to make the experiments at the moments due to lack of the materials and required equipment. However, there will be made analytical calculations, divided into three main stages: calculation of simplified model, where each of the metallic hoses is represented by a bounded beam, then there will be added empty cylindrical space inside along the length of each hoses, and lastly there will be added hydraulic fluid inside, which is the most similar to the real subsea umbilical working stage. Besides, there will be done some calculations to understand the effect of heat transfer in the system on subsea umbilical structure considering the fact that ambient temperature varies significantly from around $+300 \mathrm{C}$ near the surface to about $+30 \mathrm{C}$ near the sea bottom. Temperature might affect both the umbilical and hydraulic liquids transporting through it. The mathematical part is based on the variational principle of displacement, which states that virtual change of inner energy of deformation must be compensate by the same amount of external work applied to the object (Equation 1).

$$
\begin{aligned}
& \int_{V} \sigma_{i j} \delta \varepsilon_{i j} \mathrm{~d} V=\int_{S} f_{i}^{S} \delta u_{i} \mathrm{~d} S+\int_{V} f_{i}^{B} \delta u_{i} \mathrm{dV}, \\
& \varepsilon_{i j}=\frac{1}{2}\left(\frac{\partial u_{i}}{\partial x_{j}}+\frac{\partial u_{j}}{\partial x_{i}}\right)
\end{aligned}
$$

where $\sigma \mathrm{ij}$ - stress components; eij - deformation components; ui - displacement vector components; $\mathrm{xi}$ - present-position coordinates; fiS - surface forces vector components; fiB - mass forces vector components; $\mathrm{V}$ - volume of deformed object; $\mathrm{S}$ - surface of deformed object, which the surface forces were applied to.

System of original functions in matrix form includes components of displacement vector (Equation 2):

$$
\{u\}=\left\{\mathrm{u}_{1}(\mathrm{x}, \mathrm{y}, \mathrm{z}), \mathrm{u}_{2}(\mathrm{x}, \mathrm{y}, \mathrm{z}), \mathrm{u}_{3}(\mathrm{x}, \mathrm{y}, \mathrm{z})\right\}
$$

also stress vector (3): 


$$
\{\sigma\}=\left\{\sigma_{11}(\mathrm{x}, \mathrm{y}, \mathrm{z}), \sigma_{22}(\mathrm{x}, \mathrm{y}, \mathrm{z}), \sigma_{33}(\mathrm{x}, \mathrm{y}, \mathrm{z}), \tau_{12}(\mathrm{x}, \mathrm{y}, \mathrm{z}), \tau_{23}(\mathrm{x}, \mathrm{y}, \mathrm{z}), \tau_{13}(\mathrm{x}, \mathrm{y}, \mathrm{z})\right\}
$$

and deformation vector (4):

$$
\{\varepsilon\}=\left\{\varepsilon_{11}(\mathrm{x}, \mathrm{y}, \mathrm{z}), \varepsilon_{22}(\mathrm{x}, \mathrm{y}, \mathrm{z}), \varepsilon_{33}(\mathrm{x}, \mathrm{y}, \mathrm{z}), \gamma_{12}(\mathrm{x}, \mathrm{y}, \mathrm{z}), \gamma_{23}(\mathrm{x}, \mathrm{y}, \mathrm{z}), \gamma_{13}(\mathrm{x}, \mathrm{y}, \mathrm{z})\right\} .
$$

Temperature effect will be analyzed based on the principle of heat transfer through a single layer (Figure 4a) and multi-layer (Figure 4b) cylindrical bodies.

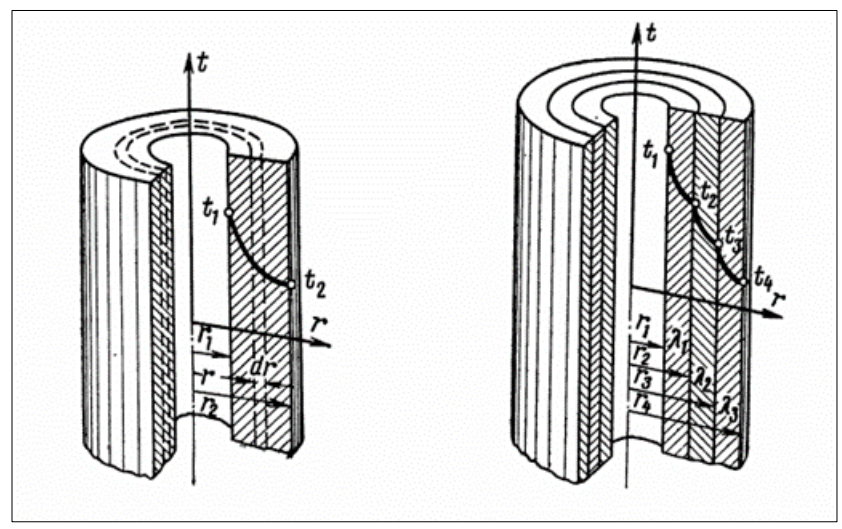

Fig. 4. Single layer (a) and multilayer (b) cylindrical structures.

In order to calculate steady-state heat transfer when through the wall of cylindrical structures it is transferred a constant amount of heat, this amount of heat going through the wall of a body with a length ' 1 ' the following formula will be used:

$$
q_{l}=\frac{2 \pi\left(t_{n}-t_{n+1}\right)}{\frac{1}{\lambda_{n}} \ln \frac{d_{n+1}}{d_{n}}}
$$

where $t_{n}, t_{n+1}$ - temperature in between the layers, $\lambda_{n}$ - heat transfer coefficient of a layer material, $\mathrm{d}$ - layer diameter.

\section{Conclusion and future research}

In conclusion, the results obtained after the computer simulation show that the second model is better than the first one in terms of axial force resistance. Moreover, the second model cross section design decreases the required outer diameter of subsea umbilical (67 $\mathrm{mm}$ and $75.8 \mathrm{~mm}$ for the second and first umbilicals, respectively), which makes this model better in terms of economic because it requires smaller amount of materials to produce the same length of umbilical than for the first model. It also significantly decreases the transportation and installation cost. Further studies will be focused on analytical verification of obtained data and analysis of heat transfer on the structural components and exploitation of subsea umbilical. 


\section{References}

1. ANSYS Worbench Features. Accessed on 20.09.2016: http://www.ansys.com/products/Structures/Impact

2. X. Chen, S. Fu, L. Song, Q. Zhong and X. Huang, Ocean Systems Eng. 3, 097 (2013)

3. I. Kozyrev, P. Zyatikov, V. Deeva, MATEC Web of Conferences 72, 01049 (2016)

4. E. Kramshonkov, A. Krainov, P. Shorohov, EPJ Web Conf. 110, 01031 (2016) 